OPEN ACCESS

Edited by:

Dwight E. Heron,

UPMC Hillman Cancer Center,

United States

Reviewed by:

Vivek Verma,

Allegheny General Hospital, United States

Jonathan Haas,

Winthrop University Hospital,

United States

*Correspondence:

Sten Myrehaug

sten.myrehaug@sunnybrook.ca

Specialty section:

This article was submitted to

Radiation Oncology,

a section of the journal

Frontiers in Oncology

Received: 11 February 2019

Accepted: 12 April 2019

Published: 01 May 2019

Citation:

Zeng KL, Tseng C-L, Soliman H,

Weiss Y, Sahgal $A$ and Myrehaug $S$

(2019) Stereotactic Body

Radiotherapy (SBRT) for

Oligometastatic Spine Metastases: An

Overview. Front. Oncol. 9:337.

doi: 10.3389/fonc.2019.00337

\section{Stereotactic Body Radiotherapy (SBRT) for Oligometastatic Spine Metastases: An Overview}

\author{
Kang Liang Zeng, Chia-Lin Tseng, Hany Soliman, Yonatan Weiss, Arjun Sahgal and \\ Sten Myrehaug* \\ Department of Radiation Oncology, Odette Cancer Centre, Sunnybrook Health Sciences Centre, Toronto, ON, Canada
}

The oligometastatic state is hypothesized to represent an intermediary state of cancer between widely metastatic disease and curable, localized disease. Advancements in radiotherapy have allowed for delivery of high precision, dose escalated treatment known as stereotactic body radiotherapy (SBRT) to targets throughout the body with excellent rates of local control. Recently, the first phase II randomized trial comparing conventional radiotherapy to comprehensive SBRT of oligometastatic disease demonstrated an overall survival and progression free survival advantage. The spine is a common site of metastasis, and a complex site for SBRT given the adjacent spinal cord and the tumor embedded within the bone tissue putting the patient at risk of fracture. Although there are expert spine SBRT guidelines for practice, there are as yet no reported randomized trials that proves superiority as compared to conventional radiation. The use of SBRT in patients with oligometastatic disease and spinal metastases is the focus of this review.

Keywords: stereotactic body radiotherapy (SBRT), oligometastases, spine metastases, response assessment, outcomes, toxicities

\section{OLIGOMETASTASES AND SBRT}

Hellman and Weichselbaum first proposed the clinical oligometastatic state in 1995 to reflect a subset of patients with limited metastatic disease (1). From the spectrum theory, this is suggested to represent an intermediary cancer state where the biological profile of a cancer may not progress to widespread metastases (2). Within this group, an opportunity arises where targeted treatment toward limited metastases may confer disease and even possibly survival advantages. Advancements in imaging techniques (i.e., MRI, PET), and development of cancer specific imaging strategies (i.e., PSMA-PET), have allowed for greater ability to identify those with oligometastatic cancer.

Select patients with oligometastatic disease to the lung and liver are considered for surgical metastectomy and within this highly selected group, observed outcomes in a non-randomized setting were promising. The International Registry of Lung Metastases included 5,206 patients over five decades, and demonstrated 5-year overall survival (OS) of 36\% after resection of limited lung metastases from mostly epithelial cancers or sarcomas (3). In colorectal patients, hepatic resection is considered for limited liver metastases with survival nearing $50 \%$ at 5 years (4).

Advancements in radiotherapy over the past decade, specifically in image-guided linear accelerator technology, treatment planning, and better understanding of normal tissue constraints with hypofractionated radiation, has led to increased interest in safe delivery of ablative doses of radiation with stereotactic body radiotherapy (SBRT). Advantages of SBRT in comparison to 
metastectomy includes the lack of surgical recovery time, side effect profile, and ability to safely target multiple metastatic lesions. SBRT may be secondarily advantageous in inducing an abscopal effect especially in malignancies strongly associated with an immune response (5).

High quality evidence supporting the role of SBRT to oligometastases with traditional endpoints such as overall survival (OS) and progression free survival (PFS) are lacking, but a significant volume of researchers are attempting to answer this question. The SABR-COMET study was presented at the 2018 American Society for Radiation Oncology annual scientific meeting and represents the first Phase 2 randomized study to report improved outcomes in targeting oligometastatic disease with SBRT (6). This study included 99 patients randomized 1:2 to palliative standard of care (SOC) treatments vs. standard of care plus SBRT to all metastatic lesions (to a maximum of 5 lesions). Median overall survival was 28 months in the SOC arm compared to 41 months in the SBRT arm $(p=0.09)$ and PFS was significantly improved (6 months in the SOC arm vs. 12 months in the SBRT arm, $p=0.001)$. The results of confirmatory Phase 3 randomized studies such as CORE, SARON, and NRGBR002 are eagerly awaited. A case demonstration of a patient treated under this approach is described in Figure 1. In the nonsmall cell lung cancer population specifically, two trials have assessed consolidative local therapy in oligometastatic disease $(7,8)$ with both noting significant improvements in progression free survival compared to maintenance therapy alone.

\section{SPINE METASTASES AND SBRT}

The spine is a common location for metastases and confers significant morbidity and mortality. The classical treatment approach for patients with symptomatic spine metastases is conventional palliative radiotherapy delivered with two parallel opposed beams with common fractionation regimens such as $8 \mathrm{~Gy}$ in 1 fraction, $20 \mathrm{~Gy}$ in 5 fractions, or $30 \mathrm{~Gy}$ in 10 fractions. Though effective in improving symptomatology, there is poor local control (LC) (9). With the availability of more lines of systemic therapy improving patient survival, there is a desire in select patients to improve durable LC and prevent neurologic compromise. Delivery of high biological effective doses (BED) of radiotherapy with SBRT precisely to the spine yields prolonged local control along with pain relief (Table 1). For those with oligometastatic disease, SBRT of known disease can prolong progression-free survival and potentially delay entry to next line of systemic therapy (29). In the post-operative setting, neurologic status is maintained through improvements in local control after SBRT. Further, following prior spine radiotherapy, it is a method of safely retreating the same or adjacent segments while minimizing dose to critical neurological structures.

Specific to spine oligometastases, Barzilai et al. reported results from the AO Spine multicenter prospective cohort Epidemiology, Process, and Outcomes of Spine Oncology (EPOSO) study (30). Patients with oligometastatic disease (defined as $<5$ metastases) showed evidence of better survival compared to those with polymetastatic disease ( $>5$ metastases). Of note, improved local control at 6 and 12 months were identified in the solitary/single spine metastasis subgroup, reflective of increased utilization of aggressive surgical and/or radiosurgery approaches.

Spine SBRT pertains unique considerations due to the balance of risk of neurologic compromise related to tumor progression and toxicities such as vertebral body fracture and myelopathy. Advancements in radiation planning and delivery, image guidance, robotic patient positioning, and understanding of dose tolerances to critical structures have made spine SBRT possible. With greater clinical experience, guidelines have been developed to direct safe practice (31-33) though supporting high-quality Phase 3 randomized data are pending. Delivery of spine SBRT requires careful patient selection, familiarity with the technique and an understanding of potential toxicities.

\section{PATIENT SELECTION}

Compared to conventional external beam radiotherapy, spine SBRT is significantly more resource intensive from both a patient and systems perspective. Multidisciplinary discussion with specialized spine surgeons, radiologists, radiation, and medical oncologists is essential for careful selection of patients to avoid treatment of those that may not benefit. Practical considerations such as funding for novel techniques must also be considered, where "payers," either that of public systems or private health insurance, may be reluctant to reimburse costly treatment modalities with limited prospective, high quality evidence justifying their use.

A number of schemes have been proposed to assist in identification of patients that benefit most from spine SBRT (34-36). Laufer et al. developed a four-point framework in the treatment of spine metastases (35). The Neurologic, Oncologic, Mechanics, and Systemic (NOMS) assessments assist in determining the optimal therapy for patients. The International Spine Oncology Consortium Report similarly proposes a multidisciplinary algorithm for the management of spine metastases given the recent advances in spine SBRT, and utilizes similar principles to guide management (34).

\section{Prognosis}

Patients with spine metastases, despite being generally thought to be incurable, represent a heterogenous population (37) where some may live many years (i.e., a patient with oligometastatic hormone responsive prostate cancer) whilst others a significantly shorter time interval (i.e., one who has failed second line systemic therapy for widely metastatic pancreatic cancer). In the former case, one may consider more aggressive techniques such as SBRT, favoring longterm local control as this patient would derive most benefit, whereas the latter patient may benefit most from conventional palliative radiotherapy (38), or possibly best supportive care alone. One should identify patients with favorable prognoses who may derive benefit from spine SBRT. Age, performance status, comorbidities, and functional capacity can assist in determination of such. The prognosis of patients as predicted by physicians is often generous, however, specific to spine 


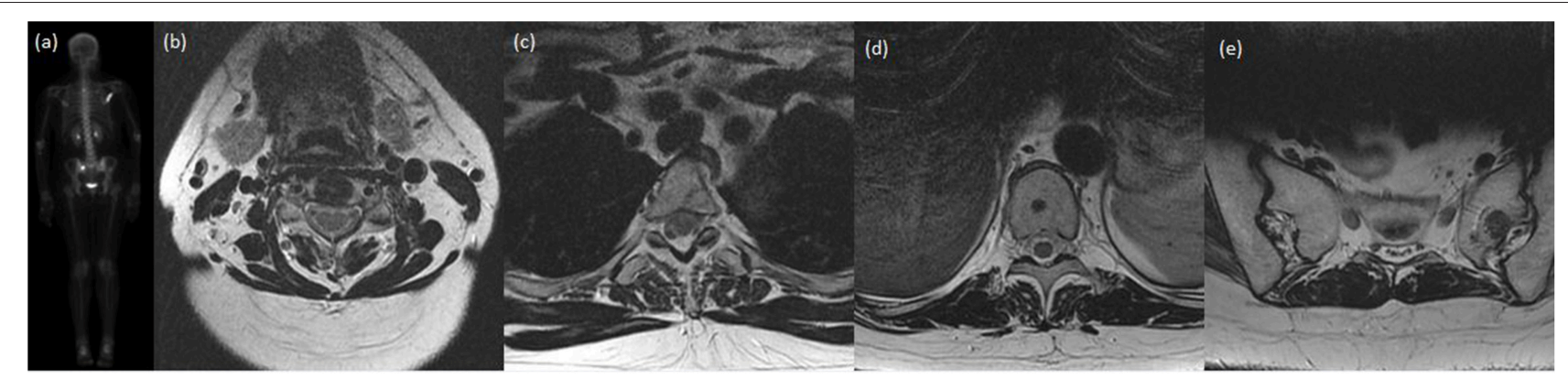

FIGURE 1 | A case presentation of a lady with invasive ductal carcinoma of the breast who was treated definitively with lumpectomy, adjuvant chemotherapy, and adjuvant radiotherapy. Shortly after completion of therapy, on re-staging investigations, she was found to have oligometastatic disease in the bones, specifically at $\mathrm{C} 4$, T3, T10, the left sacral ala, and right scapula. She received SBRT to each site and was started on hormonal therapy. At most recent follow-up 20 months later, she has not had progression of known disease nor interval development on new metastatic disease. (a) Posterior-anterior projection of pre-treatment bone scan demonstrating increased uptake within the right scapula, T3 and the right sacral ala. Subsequent images of axial slice of T2-weighted MRI demonstrating near complete marrow replacement of C4 (b), focal marrow abnormality in posterior T3 body (c), rounded focus centrally of the T10 vertebral body (d), and 13 mm lesion of left sacral ala (e).

metastases, Jensen et al. propose a Prognostic Index for Spine Metastases (PRISM) which can assist in determining the most appropriate method of treating spine metastases (39). Briefly, scoring accounts for gender, performance status, previous therapy at the intended treatment site, number of organ systems involved, time elapsed between diagnosis and metastasis, and number of spine metastasis. The scoring system categorizes patients into groups 1 (best prognosis) through 4 (worst prognosis), with median overall survivals not reached in subgroup 1, and 24.1, 13.1, and 6.5 months in groups 2,3 , and 4 , respectively.

\section{Histology}

Histologies traditionally felt to be radioresistant (renal cell carcinoma, melanoma, sarcoma) demonstrate poor tumor control rates with conventional radiotherapy techniques $(40,41)$. Spine SBRT may overcome this radioresistance. In renal cell carcinoma specifically, local control at 1year has been reported to be $>80 \%(18,42)$. As such, there is preference toward SBRT for patients with radioresistant histologies where local control is desired. In contrast, highly sensitive histologies, such as hematologic malignancies or small cell lung cancer may warrant upfront systemic therapy or derive similar benefit with conventional radiotherapy.

\section{Systemic Disease and Systemic Treatment Options}

Assessment of systemic burden of disease and the availability and response to systemic therapies can influence patients' goals of care. In patients with widely metastatic disease, there may be an urgency to proceed with systemic therapy over focal treatment of minimally symptomatic spinal disease. Further, the availability of further lines of systemic treatment options is intimately related to prognosis, and clinicians may favor conventional techniques in those with high visceral burden of disease with limited further options or prognosis.

\section{Stability and Epidural Spinal Cord Compression}

Mechanical spinal instability and presence of high-grade epidural spinal cord compression (ESCC) are independent indications for potential surgical intervention; radiotherapy, either with SBRT or conventional techniques may not be the most appropriate upfront in patients with reasonable prognoses.

Mechanical instability is usually not corrected with radiotherapy alone. As a method of grading instability, the Spinal Instability Neoplastic Score (SINS; Table 2) is a validated assessment tool of spine disease which may warrant surgical intervention (43-45). This score considers location, presence of mechanical pain, type of bony lesion, spinal alignment, vertebral body collapse, and posterolateral involvement and generates a score ranging from 0 to 18 , with stable segment scores between 0 and 6 , potentially unstable segments scoring between 7 and 12, and unstable lesions between 13 and 18. Potentially unstable and unstable lesions may warrant surgical evaluation.

In the case of epidural disease, the degree of ESCC and its potential consequences such as myelopathy or radiculopathy must be evaluated. Grading the severity of ESCC is commonly done via the Bilsky score, which facilitates communication between health-care providers (46). SBRT may be a more appropriate treatment option for those patients with appropriately graded low volume epidural disease. However, in the setting of acute clinical changes and/or high grade ESCC (Bilsky 2 or 3, and possibly 1c) patients warrant surgical evaluation. Consideration can be made to separation surgery, in which surgery to establish the epidural space is performed, followed by SBRT (47).

\section{Post-operative SBRT}

High grade ESCC and/or mechanical instability often warrants surgical intervention in the appropriate patient population. In this setting, significant rates of local recurrence (up to $69.3 \%$ at 1-year) (48) justifies adjunctive therapies. Post-operative radiotherapy has traditionally been delivered with conventional techniques (49), although recently SBRT in this setting has 
TABLE 1 | Outcomes after spine SBRT for de novo metastases.

\begin{tabular}{|c|c|c|c|c|c|c|}
\hline References & $\begin{array}{l}\text { Patients/spinal } \\
\text { segments }(n / n)\end{array}$ & Histology & $\begin{array}{l}\text { Dose fractionation } \\
\text { [dose (Gy)/fractions] }\end{array}$ & $\begin{array}{l}\text { Follow-up duration } \\
\text { (median, months) }\end{array}$ & $\begin{array}{l}\text { Local control } \\
\text { (time, if available) }\end{array}$ & Pain response \\
\hline $\begin{array}{l}\text { Tseng et al. } \\
(10)\end{array}$ & $145 / 279$ & Mixed & $24 / 2$ & 15 & $\begin{array}{l}90.3 \% \text { (1-year) } \\
82.4 \% \text { (2-years) }\end{array}$ & NR \\
\hline $\begin{array}{l}\text { Azad et al. } \\
\text { (11) }\end{array}$ & $25 / 25$ & Mixed & $15-25.5 / 1-5$ & 18 & $84 \%$ & $2 / 3$ had pain relief \\
\hline $\begin{array}{l}\text { Anand et al. } \\
(12)\end{array}$ & $52 / 76$ & Mixed & $24-27 / 1-3$ & 8.5 & $\begin{array}{l}94 \% \text { (1-year) } \\
83 \% \text { (2-years) }\end{array}$ & 90-94\% complete pain relief \\
\hline $\begin{array}{l}\text { Bishop et al. } \\
\text { (13) }\end{array}$ & $285 / 332$ & Mixed & $\begin{array}{l}\text { Median tumor dose 43 Gy } \\
(B E D, a / b=10)\end{array}$ & 19 & $\begin{array}{l}88 \% \text { (1-year) } \\
82 \% \text { (3-years) }\end{array}$ & NR \\
\hline $\begin{array}{l}\text { Sellin et al. } \\
(14)\end{array}$ & $37 / 40$ & $\mathrm{RCC}$ & $24-30 / 1-5$ & 49.0 & $57 \%$ & $41 \%$ report pain improvement \\
\hline $\begin{array}{l}\text { Bate et al. } \\
\text { (15) }\end{array}$ & $24 / 24^{\star}$ & Mixed & $16-30 / 1-5$ & 9.8 & $96 \%$ (1-year) & NR \\
\hline $\begin{array}{l}\text { Sohn et al. } \\
(16)\end{array}$ & $13 / 13$ & $\mathrm{RCC}$ & 38/4 (median) & NR & $86 \%$ (1-year) & $\begin{array}{l}77 \% \text { overall ( } 23 \% \text { complete pain } \\
\text { response) }\end{array}$ \\
\hline $\begin{array}{l}\text { Guckenberger } \\
\text { et al. (17) }\end{array}$ & $301 / 387$ & Mixed & $10-60 / 1-20$ & 11.8 & $\begin{array}{l}90 \% \text { (1-year) } \\
84 \% \text { (2-years) }\end{array}$ & $\begin{array}{l}44 \% \text { with severe pre-treatment } \\
\text { pain, pain free. } 56 \% \text { with } \\
\text { mild/moderate pre-treatment } \\
\text { pain, pain free. }\end{array}$ \\
\hline $\begin{array}{l}\text { Thibault et al. } \\
\text { (18) }\end{array}$ & $51 / 51^{\star}$ & $\mathrm{RCC}$ & $18-30 / 1-5$ & 12.3 & $\begin{array}{l}83 \% \text { (1-year) } \\
66 \% \text { (2-years) }\end{array}$ & NR \\
\hline $\begin{array}{l}\text { Garg et al. } \\
\text { (19) }\end{array}$ & $47 / 47$ & Mixed & $16-24 / 1$ & 17.8 & 88\% (18 months) & $\begin{array}{l}18 \text { patients pain-free } \\
\text { post-treatment compared to } 13 \\
\text { patients pre-treatment }\end{array}$ \\
\hline $\begin{array}{l}\text { Chang et al. } \\
(20)\end{array}$ & $93 / 131$ & Mixed & NR & 23.7 & 89\% (1-year) & NR \\
\hline Gill et al. (21) & $14 / 14^{\star}$ & Mixed & $30-35 / 5$ & 34 & $\begin{array}{l}80 \% \text { (1-year) } \\
73 \% \text { (2-years) }\end{array}$ & NR \\
\hline $\begin{array}{l}\text { Wang et al. } \\
(22)\end{array}$ & $149 / 166$ & Mixed & $27-30 / 3$ & 15.9 & $\begin{array}{l}81 \% \text { (1-year) } \\
72 \% \text { (2-years) }\end{array}$ & $\begin{array}{l}54 \% \text { pain free at } 6 \text {-months, } \\
\text { compared to } 26 \% \text { at baseline }\end{array}$ \\
\hline $\begin{array}{l}\text { Staehler et al. } \\
\text { (23) }\end{array}$ & $55 / 105$ & RCC & $19-20 / 1$ & 33.4 & $\begin{array}{l}94 \% \text { (1-year) } \\
90 \% \text { (2-years) }\end{array}$ & $\begin{array}{l}\text { Median pre-treatment score } 5 \text {, } \\
\text { median post-treatment score } 01 \\
\text { week after }\end{array}$ \\
\hline $\begin{array}{l}\text { Sahgal et al. } \\
(24)\end{array}$ & $14 / 18$ & Mixed & 24/3 (median) & 9 & $72 \%$ & NR \\
\hline $\begin{array}{l}\text { Yamada et al. } \\
(25)\end{array}$ & $93 / 103$ & Mixed & $18-24 / 1$ & 15 & 93\% (2-years) & NR \\
\hline $\begin{array}{l}\text { Chang et al. } \\
\text { (26) }\end{array}$ & $17 / 22$ & Mixed & $27-30 / 3-5$ & NR & $68 \%$ & $\begin{array}{l}\text { Narcotic usage fell from } 60 \% \text { at } \\
\text { baseline to } 36 \% \text { at } 6 \text { months }\end{array}$ \\
\hline $\begin{array}{l}\text { Gerszten } \\
\text { et al. (27) }\end{array}$ & $8 / 8^{*}$ & Breast & $15-22.5 / 1$ & 16 & $100 \%$ & $\begin{array}{l}\text { Long-term axial and radicular } \\
\text { pain improvement occurred in } \\
96 \% \text { who were treated primarily } \\
\text { for pain }\end{array}$ \\
\hline Ryu et al. (28) & $49 / 61$ & Mixed & $10-16 / 1$ & NR & 96\% (9-months) & Overall response 85\% \\
\hline
\end{tabular}

NR, not reported; *Assuming one segment per patient.

been explored (50). Overall, post-operative SBRT was well tolerated [no grade 3 or 4 toxicities, $3.8 \%$ rate of grade $1 / 2$ gastrointestinal and genitourinary toxicities, $9 \%$ rate of pain flare and vertebral compression fracture (VCF)] with excellent one-year local control between 84 and $88 \%$ reported $(47,51)$.

\section{SPINE SBRT TECHNIQUE}

Safe delivery of high doses of radiation to the spine is imperative to avoid potentially catastrophic neurologic sequelae. Recent advances in treatment planning, immobilization, treatment delivery and a better understanding of toxicities associated with SBRT have allowed for advancements within this field (Figure 2). Near rigid patient immobilization, consensus treatment volume definitions, and image-guidance are key for delivery of spine SBRT (52).

Near rigid patient immobilization is required to allow for inter-fraction reproducibility and minimize planning target volumes, to sculpt dose to intended targets and avoid neurologic toxicities. Many methods of immobilization have been explored which must consider patient comfort during relatively long 
TABLE 2 | Spinal instability neoplastic score (SINS).

\begin{tabular}{|c|c|c|}
\hline Category & Description & Score \\
\hline \multirow[t]{4}{*}{ Location } & Junctional (occiput-T2, C7-T2, T11-L1, L5-S1) & 3 \\
\hline & Mobile (C3-C6, L2-4) & 2 \\
\hline & Semirigid (T3-T10) & 1 \\
\hline & Rigid (S2-S5) & 0 \\
\hline \multirow[t]{3}{*}{ Pain } & Yes & 3 \\
\hline & Occasional non-mechanical pain & 1 \\
\hline & No & 0 \\
\hline \multirow[t]{3}{*}{ Bone lesion } & Lytic & 2 \\
\hline & Mixed lytic/blastic & 1 \\
\hline & Blastic & 0 \\
\hline \multirow[t]{3}{*}{ Alignment } & Subluxation/translation & 4 \\
\hline & De novo deformity & 2 \\
\hline & Normal & 0 \\
\hline \multirow[t]{4}{*}{ Vertebral body } & $>50 \%$ collapse & 3 \\
\hline & $<50 \%$ collapse & 2 \\
\hline & No collapse but $>50 \%$ involvement by tumor & 1 \\
\hline & None of the above & 0 \\
\hline \multirow[t]{3}{*}{ Posterolateral involvement } & Bilateral & 3 \\
\hline & Unilateral & 1 \\
\hline & None & 0 \\
\hline
\end{tabular}

*The SINS score adapted from Fisher et al. (39).

simulation and treatment times. The physiologic motion of the spinal cord is $<0.5 \mathrm{~mm}$ in all directions (53), which is relatively insignificant compared to potential gross patient motion. Our practice is acquisition of a treatment scanning CT scan with patients secured using a BodyFIX device (Elekta AB, Stockholm, Sweden) which has demonstrated reproducibility within $1.2 \mathrm{~mm}$ and $0.9^{\circ}$ with $95 \%$ confidence (52). Other immobilization devise include custom cradles (25) and stereotactic body frames (54).

Intra-fraction motion is a further consideration due to potentially long treatment times and patient comfort. Using either an evacuated cushion, vacuum body fixation or thermoplastic S-frame mask for lesions treated above T3, Li et al. performed pre-treatment verification cone beam $(\mathrm{CBCT})$ as well as mid-fraction and post-treatment СBCT. The authors found margins required to encompass residual setup errors to be within $2 \mathrm{~mm}$ with vacuum body fixation and $3 \mathrm{~mm}$ with the other systems (55). Another study found a $3 \mathrm{~mm}$ planning margin to be sufficient to account for both intra-fraction and inter-fraction motion, with greatest intra-fraction motion in the $\mathrm{x}$-plane of $0.7 \mathrm{~mm}$ (95\% confidence interval 0.5-1.0 mm) (56).

After acquisition of planning CT scan, axial T1 and T2 weighted volumetric MRI sequences are fused to aid in target and critical neural structure delineation. In those cases where MRI is contraindicated or uninformative, CT myelogram may be an alternative.

The International Spine Radiosurgery Consortium has published consensus guidelines for target delineation in spine SBRT based on expert opinion with 10 representative cases (57). In general, gross tumor volume (GTV) should utilize all available imaging modalities and include epidural and paraspinal disease extension. The clinical target volume (CTV) should include areas of potential microscopic extension. In general, if GTV were present within the vertebral body, pedicle, transverse process, lamina, spinous process, the entire region should be included. In addition, as a rule of thumb, the adjacent potential bony region should be included. For example, GTV involving the vertebral body and right pedicle should correspondingly expand to a CTV encompassing the entire vertebral body, right pedicle, right transverse process and right lamina. With bone only disease, extraosseous expansion of CTV volumes should not be necessary, specifically into the epidural space or paraspinal soft tissue spaces. The planning target volume (PTV) was suggested to be a uniform expansion of $\leq 3 \mathrm{~mm}$, depending on immobilization and image guidance technique.

In a separate study of post-operative epidural progression following SBRT, Chan et al. found that post-operative epidural disease extent underestimated treatment volumes and that consideration of pre-operative disease is crucial to prevent subsequent progression (58). An international group of experts led by Redmond et al. generated consensus contouring guidelines for post-operative spine SBRT (59). Recommendations were to include the entire pre-operative extent of both bony and epidural disease and immediately adjacent bony structures as part of the CTV. With circumferential epidural disease specifically, a "donut" shaped CTV was applied regardless of the post-operative epidural disease extent. Surgical instrumentation was suggested to be excluded from the CTV.

Optimal dose fractionation for spine SBRT is unknown. Common fractionation schemes include 16-24 Gy/1 fraction, 24 Gy/2 fractions, 24-30 Gy/3 fractions, 30 Gy/4 fractions, and 30-40 Gy/5 fractions. Considerations includes risk of vertebral compression fracture [up to $39 \%$ risk with single fractions (60)] and treatment volume, where very large tumors may warrant $4-5$ fraction courses. Single fractions of $15 \mathrm{~Gy}$ are effective, however, may be related to increased toxicities such as VCF, pain flare and myelopathy, and fractionation may reduce this (61). Our standard practice is a course of 24-28 Gy in 2 fractions or 30 Gy in 4 fractions for larger tumors, to maintain an acceptable fracture risk of $10 \%$.

There are differences in SBRT treatment planning compared to conventional techniques and Task Group 101 of The American Association of Physicists in Medicine outlines best practices (62). Perhaps the greatest change is allowing hotspots within treatment targets and the requirement for sharp drop-offs especially near organs at risk. As such, CTV and PTV margins are significantly smaller, whilst delivery with non-overlapping and possibly coplaner beams allow for sharp dropoff. Relating to spine SBRT specifically, there is an absolute requirement to not violate the thecal sac and spinal cord PRV dose limits for the sake of preventing catastrophic neurologic sequelae $(63,64)$. As such, it is acceptable for PTV coverage to be compromised.

Once a treatment plan has been generated, assessment of patient positioning on the treatment unit should be conducted. Image verification is completed with cone-beam $\mathrm{CT}$ after patient set-up. A Hexapod robotic couch (Medical Intelligence, Schwabmuenchen, Germany) facilitates set-up correction with 


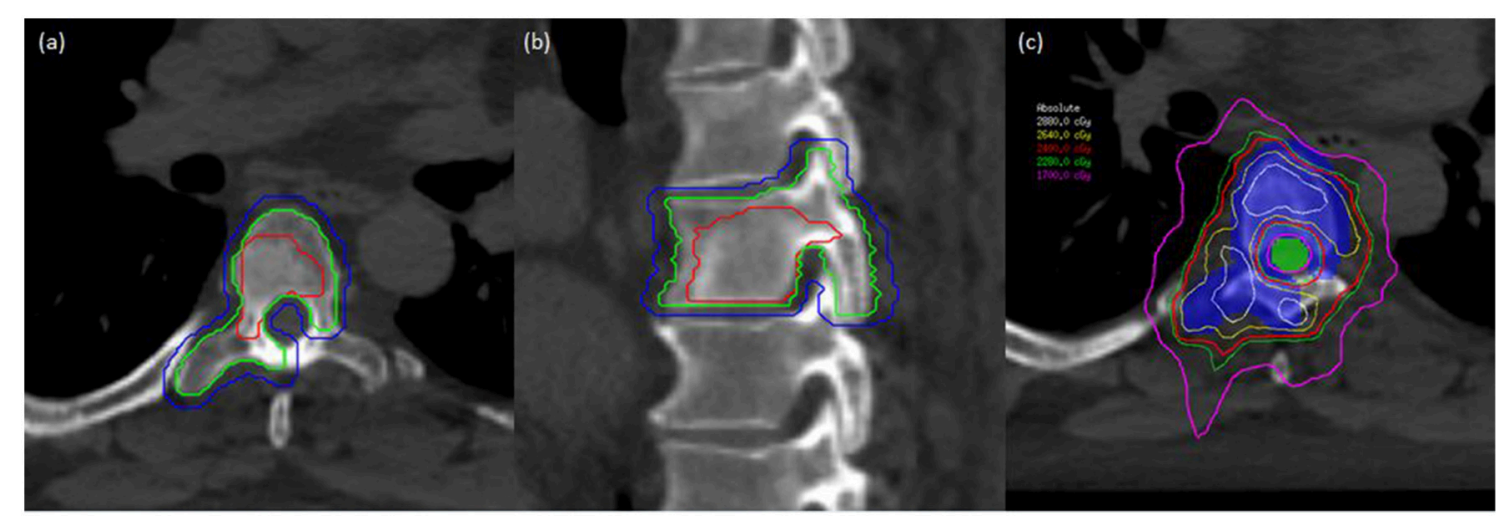

FIGURE 2 | A man with oligometastatic castrate-resistant prostate cancer with painful spine metastases. This man was treated to 24 Gy in 2 fractions. (a) Axial planning CT scan demonstrating T6 vertebral level with gross tumor volume (GTV), clinical target volume (CTV), and planning target volume (PTV) delineated with red, green, and blue lines, respectively. (b) Sagittal planning CT demonstrating T6 vertebral level with GTV, CTV, and PTV in red, green, and blue, respectively. (c) Dose distribution at the level of T6 with PTV (colorwash blue) and spinal cord planning organ at risk volume (PRV) in colorwash green. Demonstration of sharp-dose fall-off to respect critical structures while allowing coverage of the target volumes.

six degrees of freedom. Subsequent CBCT can then be acquired for assessment of residual setup error, and intrafraction and posttreatment periods to ensure geometric stability. Other image verification techniques include CT-on-rails (65) and Cyberknife tracking (66).

\section{OUTCOMES}

\section{Response Assessment}

Assessment of response post-spine SBRT is challenging as criteria such as RECIST 1.1 are difficult to apply, and tumor specific phenomena exist whereby imaging must be interpreted with caution and with familiarity of expected changes after treatment. MRI signal changes creating a pseudoprogression phenomenon, as first seen following treatment of brain tumors, can occur after spine SBRT. Rather than true progression which demonstrates consistent growth over time, the radiographical appearance of pseudoprogression subsequently subsides on serial imaging. The incidence of pseudoprogression has been reported in the range of $14-37 \%$ and risk factors include lytic tumors, earlier volume enlargement, greater GTV to reference non-irradiated vertebral body T2 intensity ratio, and growth confined to $80 \%$ of the prescription isodose line (67-69).

In response to the need for common criteria assessing response post-spine SBRT, a group of international experts devised the SPIne response assessment in Neuro-Oncology (SPINO) guidelines as a method of standardized reporting (70). Recommendations of imaging response include spine MRI every 2-3 months for the first 12-18 months then every 3-6 months thereafter, interpreted by a radiologist and radiation oncologist jointly treating patients with this technique. Progression is defined as gross increases in tumor volume, new tumors in epidural space, and neurologic deterioration due to known epidural disease. Where progression is questionable, serial imaging and consideration of tissue biopsy should be made to rule out pseudoprogression. Assessment of pain response should be conducted with the Brief Pain Inventory at 3 months posttreatment adopting the consensus guidelines published by the International Bone Metastases Consensus Working Party (71).

\section{Local Control}

Treatment of de-novo metastases with spine SBRT yields favorable local control, in the range of $80-95 \%$ in a heterogenous patient population, treated with a number of dose/fractionation regiments ranging from a single $15 \mathrm{~Gy}$ fraction to $30 \mathrm{~Gy}$ in 3 fractions $(19,22,72)$. In a review of nearly 1,400 patients following SBRT, Hall et al. report overall local control of 90\% at 15 months (73). The largest single institutional experience utilizing $24 \mathrm{~Gy}$ in 2 fractions as standard for de novo metastases included 279 spinal segments from 145 consecutive patients (10). Local control at 1 - and 2-years was 90.3 and $82.4 \%$ with excellent reported safety. There is a relative reduction in 2-year compared to 1 -year LC ranging from 66 to $93 \%$ (Table 1). This may reflect the heterogenous nature of the mentioned studies, however merits further investigation. Though control rates at 2-years are still higher than with conventional palliative radiotherapy, in patients with limited metastatic disease and relatively excellent clinical status, durable LC is the treatment goal and endpoints beyond 1-year may be of further interest. In patients who do have local progression at this time point, retreatment with spine SBRT is safe and does offer excellent outcomes, though patients should be discussed in the multidisciplinary setting.

Retrospective studies have explored local control with a specific interest in traditionally radioresistant histologies that typically exhibit poor control with conventional external mean radiotherapy. One-year local control of $83 \%$ was reported after treatment of renal cell carcinoma (RCC) spine metastases treated with most common dose of $24 \mathrm{~Gy}$ in 2 fractions (18). Ghia et al. also report similar 1 -year LC of $82 \%$ in RCC, and found that multi-fraction courses yielded inferior outcomes compared to single-fraction (sub-hazard ratio 6.57) which may suggest that $\mathrm{BED}$ escalation may be advantageous in radioresistant histologies 
(74). The high rates of local control are replicated in patients with sarcoma (75) and melanoma (76).

In the post-operative setting, inclusion of spine SBRT yields excellent local control, similar to de-novo metastases. Following vertebrectomy or laminectomy, 1-year LC in has been reported to be $>80 \%$ in multiple studies $(47,77)$. In those where downgrading of epidural disease is surgically possible, local control is further improved (51). The considerations and treatment techniques are summarized in a critical review of post-operative spine SBRT by Redmond et al. (78).

Palliation of spine metastases with conventional techniques is limited by cumulative doses tolerated by the spinal cord. Despite high probability of pain response after conventional retreatment (79), local control remains poor which may become problematic for those with favorable prognoses. Especially in the modern setting of additional lines of systemic therapies that are potentially more efficacious, there is an increasing need to safely deliver retreatment to spine metastases. In a systematic review, local control after SBRT in this setting ranged from 66 to $90 \%$ at 1 -year and improvement in pain scores post treatment ranged from 65 to $81 \%$ (80). Importantly, reirradiation was safe; vertebral fracture rate was $12 \%$ and treatment related myelopathy was $1.2 \%$. Hashmi et al. pooled outcomes after retreatment with SBRT in 7 institutions (81). The median initial conventional radiotherapy delivered was $30 \mathrm{~Gy}$ in 10 fractions and $60 \%$ were re-treated with a single fraction SBRT. Local control remained excellent at $83 \%$ and importantly, there were no cases of radiation myelopathy after treatment of 247 spinal segments.

\section{Pain Response and Quality of Life}

Overall pain response after conventional palliative radiotherapy is $\sim 62 \%$ regardless of fractionation schedule, with complete response rates of $24 \%$ (38). The duration of response can be for months, with retreatment considered after 4 weeks, which may be effective despite initial non-response (82). In spine SBRT, complete pain response ranging between 46 and $92 \%$ have been reported $(42,83)$.

It is hypothesized that delivery of higher BED of radiotherapy to the spine may yield improved pain response. It is unclear the optimal dose fractionation for pain response specifically, and whether this technique offers improvements in pain response compared to conventional radiotherapy. Recently, Sprave et al. conducted a randomized phase II trial with the endpoint of pain-control, enrolling 55 patients treated with either SBRT (24 Gy in a single fraction) vs. 3D conformal radiotherapy to a dose of $30 \mathrm{~Gy}$ in 10 fractions (84). The authors assessed response using the parameters as established by the International Bone Consensus Working Party (71). There was a trend toward improved complete response at 3 months ( 43 vs. $17 \%, p=0.0568$ ) and at 6 months, rates of complete response were significantly higher in the SBRT group (53 vs. $10 \%, p=0.0034$ ). Responses were also more durable after SBRT. The vertebral compression fracture risk was $8.7 \%$ at 3 months and $27.8 \%$ at 6 months. There were no grade $\geq 3$ adverse events reported. This continues to be assessed in the randomized phase II/III setting with the ongoing NCIC CTG SC.24 trial comparing conventional palliative radiotherapy to a standardized spine SBRT dose of
$24 \mathrm{~Gy}$ in 2 fractions and RTOG 0631 comparing a single fraction of $16 \mathrm{~Gy}$ vs. conventional 8 Gy in 1 fraction $(85,86)$.

In a multi-institutional, international analysis of 387 spine segments treated with a median dose of $28 \mathrm{~Gy}$ in 3 fractions, over $40 \%$ of patients with severe pretreatment pain were pain free (definitionally a complete response assuming no increase in analgesic intake) at last follow-up with a median followup duration of 11.5 months (87). Pain improvement after retreatment with SBRT has similarly reported to be high (66).

Quality of life (QOL) is an important endpoint which is frequently assessed in addition to physical symptom outcomes and radiographic disease status. Sprave et al. assessed QOL using validated instruments including the EORTC QLQ-BM22, QLQFL13, and QSC-R10 and found that QOL was not worse after SBRT for spine metastases compared to conventional palliative radiotherapy (88). This endpoint will also be assessed in the ongoing NCIC CTG.SC24 phase II/III clinical trial.

\section{Predictors of Failure}

Progression after spine SBRT is most common within the epidural space and may reflect the relative underdosing of tumor when intimate with thecal sac, or inherent biological aggressiveness of spine metastases with epidural components $(51,89)$. Al-Omair et al. found that surgical downgrading epidural disease extent resulted in improved local control prior to spine SBRT (51). Methods of mitigating this influence on local control include considering escalating the allowable dose to the spinal cord, or interventional surgical techniques to target epidural disease extension.

\section{TOXICITIES}

Spine SBRT is generally well-tolerated, and typically a threshold of $<5 \%$ is accepted as risk of serious adverse events such as myelopathy. VCF rates have been relatively well-studied after spine SBRT, and a greater understanding of pretreatment assessment and radiotherapy technique has mitigated this risk.

\section{Pain Flare}

Defined as a transient increase in pain shortly after commencing or completing radiotherapy, pain flare is common in approximately a third of patients after conventional palliative radiotherapy (90). The range of patients developing pain flare after spine SBRT is significant, from 14 to $68 \%$ (9193). Dexamethasone has been prospectively evaluated in the prevention of pain flare and reduced its rate from 68 to 19\% (94).

\section{Vertebral Compression Fracture}

Delivery of a high BED of radiotherapy generates an intense acute inflammatory effect that is hypothesized to weaken the bony matrix and place patients at risk of VCF (60). The rate of VCF in the range of $11-39 \%$ with a crude risk of $13.9 \%$ in a review $(60,95,96)$, compared to $3 \%$ for conventional radiotherapy (97). Regardless of the mechanism of VCF, both pre-treatment characteristics and treatment related parameters influence the rate of VCF that can result in further pain, and requirement for surgical stabilization. Median time to development of VCF 
was 2.5 months in a multi-institutional study including 57 fractures (98).

In retrospective analyses, the aforementioned SINS score includes several elements predictive of VCF including baseline fracture, lytic disease, spine malalignment, $>50 \%$ vertebral involvement and the overall high SINS score was similarly predictive (60). Lee et al. assessed the capability of SINS in predicting fracture, and found that those in the high SINS group to have a $66.3 \%$ risk of fracture at 24 months compared to $21.3 \%$ for the low SINS group (99). Further, volume of lytic disease, a refinement of the SINS component, has independently been demonstrated to predict for SBRT-inducted VCF (100). These data support multidisciplinary assessment of patients with spinal metastases, especially in those with intermediate/high SINS scores who may benefit from surgical or minimally invasive procedures to stabilize the spine prior to radiotherapy.

High dose, single-fraction SBRT has been associated with a higher rate of VCF. Those receiving a single fraction of $\geq 24 \mathrm{~Gy}$, compared to those receiving $20-23 \mathrm{~Gy}$ and those receiving $\leq 20$ Gy had a $39 \%$ vs. $23 \%$ vs. $11 \%$ risk of fracture, respectively. In support of this, Rose et al. report a fracture rate of 39\% after single doses ranging from 18 to $24 \mathrm{~Gy}$ (96). Our institution has observed an 8.5\% 1-year VCF risk utilizing our standard 24 Gy in 2 fraction technique.

Sprave et al. assessed bone mineral density as a prespecified secondary endpoint in their study comparing conventional palliative radiotherapy to spine SBRT (101). Both conventional radiotherapy and SBRT increased bone mineral density at 3- and 6-months with one technique not being statistically significantly better. In osteolytic metastases specifically, SBRT increased bone density whereas conventional RT did not. These findings support the safety of spine SBRT, especially where vertebral body fracture is a consideration.

\section{Myelopathy}

Radiation myelopathy is a late complication of SBRT and most feared due to potential catastrophic outcomes. A review of nearly 1,400 patients reveal that rates of myelopathy to be $0.4 \%$ (73). Point max doses to the spinal cord categorized by number of fractions was reported in a study of nine cases of myelopathy compared to 66 cases without by Sahgal et al. (102). With two fractions, a point max dose of 12.5, 14.6, 15.7, 16.4,

\section{REFERENCES}

1. Hellman S, Weichselbaum RR. Oligometastases. J Clin Oncol Off J Am Soc Clin Oncol. (1995) 13:8-10.

2. Hellman S. Karnofsky Memorial Lecture. Natural history of small breast cancers. J Clin Oncol Off J Am Soc Clin Oncol. (1994) 12:2229-34.

3. Pastorino U, Buyse M, Friedel G, Ginsberg RJ, Girard P, Goldstraw P, et al. Long-term results of lung metastasectomy: Prognostic analyses based on 5206 cases. J Thorac Cardiovasc Surg. (1997) 113:37-49.

4. Nordlinger B, Guiguet M, Vaillant JC, Balladur P, Boudjema K, Bachellier $\mathrm{P}$, et al. Surgical resection of colorectal carcinoma metastases to the liver. A prognostic scoring system to improve case selection, based on 1568 patients. Association Française de Chirurgie. Cancer. (1996) 77:1254-62. and 17.0 Gy yielded an estimated risk of 1, 2, 3, 4, and 5\% of myelopathy, respectively. In the reirradiation setting, after conventional external beam radiotherapy, a cumulative thecal sac point maximum dose of $70 \mathrm{~Gy}$ in equivalent $2 \mathrm{~Gy}$ per fractions (utilizing an alpha-beta ratio of 2) was suggested as long as sufficient time had elapsed since initial treatment ( $\geq 5$ months) and the point maximum for retreatment should not exceed $25 \mathrm{~Gy}$ in equivalent $2 \mathrm{~Gy}$ fractions (101).

\section{CONCLUSIONS}

The recent, first randomized clinical trial demonstrated overall and progression free survival benefits after SBRT to oligometastatic disease which supports prior retrospective case series (6). The spine is a common site of metastatic bone disease, and as high quality data continue to mature, along with completion of additional randomized clinical trials, it is expected that utility of SBRT to the spine will increase in the future.

Spine SBRT is unique due to the requirement of sharp dose falloff to prevent serious neurologic morbidity. With recent advances in radiotherapy planning, robotic patient positioning, image guidance and radiotherapy delivery, this has been made possible. Local control is excellent, and pain response is comparable to conventional radiotherapy. Patient selection is of utmost importance due to this resource intensive technique, and multidisciplinary consultation is warranted.

\section{AUTHOR CONTRIBUTIONS}

$\mathrm{KZ}$, AS, and SM were responsible for the conception of this review. $\mathrm{KZ}$ and $\mathrm{SM}$ were primarily involved in the abstraction and analysis of data. All authors contributed to the writing of this review, editing, and final approval prior to submission.

\section{FUNDING}

SM has received honoraria from Novartis and Ipsen. HS has received honoraria from Elekta $\mathrm{AB}$, $\mathrm{AS}$ has received honorarium for previous educational seminars from Medtronic Kyphoplasty Division and Elekta $\mathrm{AB}$, research grants from Elekta AB.
5. Postow MA, Callahan MK, Barker CA, Yamada Y, Yuan J, Kitano S, et al. Immunologic correlates of the abscopal effect in a patient with melanoma. $N$ Engl J Med. (2012) 366:925-31. doi: 10.1056/NEJMoa1112824.

6. Palma DA, Olson R, Harrow S, et al. Stereotactic ablative radiotherapy versus standard of care palliative treatment in patients with oligometastatic cancers (SABR-COMET): a randomised, phase 2, open-label trial. Lancet. (2019). doi: 10.1016/S0140-6736(18)32487-5. [Epub ahead of print].

7. Gomez DR, Blumenschein GR, Lee JJ, Hernandez M, Ye R, Camidge $\mathrm{DR}$, et al. Local consolidative therapy versus maintenance therapy or observation for patients with oligometastatic non-small-cell lung cancer without progression after first-line systemic therapy: a multicentre, randomised, controlled, phase 2 study. Lancet Oncol. (2016) 17:1672-82. doi: 10.1016/S1470-2045(16)30532-0 
8. Iyengar P, Wardak Z, Gerber DE, Tumati V, Ahn C, Hughes RS, et al. Consolidative radiotherapy for limited metastatic non-small-cell lung cancer: a phase 2 randomized clinical trial. JAMA Oncol. (2018) 4:e173501. doi: 10.1001/jamaoncol.2017.3501

9. Nguyen J, Chow E, Zeng L, Zhang L, Culleton S, Holden L, et al. Palliative response and functional interference outcomes using the Brief Pain Inventory for spinal bony metastases treated with conventional radiotherapy. Clin Oncol. (2011) 23:485-91. doi: 10.1016/j.clon.2011.01.507

10. Tseng C-L, Soliman H, Myrehaug S, Lee YK, Ruschin M, Atenafu EG, et al. Imaging-based outcomes for $24 \mathrm{~Gy}$ in 2 Daily fractions for patients with de novo spinal metastases treated with spine Stereotactic Body Radiation Therapy (SBRT). Int J Radiat Oncol Biol Phys. (2018) 102:499-507. doi: 10.1016/j.ijrobp.2018.06.047

11. Azad TD, Esparza R, Chaudhary N, Chang SD. Stereotactic radiosurgery for metastasis to the craniovertebral junction preserves spine stability and offers symptomatic relief. J Neurosurg Spine. (2016) 24:241-7. doi: 10.3171/2015.6.SPINE15190

12. Anand AK, Venkadamanickam G, Punnakal AU, Walia BS, Kumar A, Bansal AK, et al. Hypofractionated stereotactic body radiotherapy in spinal metastasis - with or without epidural extension. Clin Oncol. (2015) 27:34552. doi: 10.1016/j.clon.2015.01.035

13. Bishop AJ, Tao R, Rebueno NC, Christensen EN, Allen PK, Wang XA, et al. Outcomes for spine stereotactic body radiation therapy and an analysis of predictors of local recurrence. Int J Radiat Oncol Biol Phys. (2015) 92:101626. doi: 10.1016/j.ijrobp.2015.03.037

14. Sellin JN, Reichardt W, Bishop AJ, Suki D, Rhines LD, Settle SH, et al. Factors affecting survival in 37 consecutive patients undergoing de novo stereotactic radiosurgery for contiguous sites of vertebral body metastasis from renal cell carcinoma. J Neurosurg Spine. (2015) 22:52-9. doi: 10.3171/2014.9.SPINE1482

15. Bate BG, Khan NR, Kimball BY, Gabrick K, Weaver J. Stereotactic radiosurgery for spinal metastases with or without separation surgery. $J$ Neurosurg Spine. (2015) 22:409-15. doi: 10.3171/2014.10.SPINE14252.

16. Sohn S, Chung CK, Sohn MJ, Chang U-K, Kim SH, Kim J, et al. Stereotactic radiosurgery compared with external radiation therapy as a primary treatment in spine metastasis from renal cell carcinoma: a multicenter, matched-pair study. J Neurooncol. (2014) 119:121-8. doi: 10.1007/s11060-014-1455-9

17. Guckenberger M, Mantel F, Gerszten PC, Flickinger JC, Sahgal A, Létourneau $\mathrm{D}$, et al. Safety and efficacy of stereotactic body radiotherapy as primary treatment for vertebral metastases: a multi-institutional analysis. Radiat Oncol Lond Engl. (2014) 9:226. doi: 10.1186/s13014-014-0226-2

18. Thibault I, Al-Omair A, Masucci GL, Masson-Côté L, Lochray F, Korol $\mathrm{R}$, et al. Spine stereotactic body radiotherapy for renal cell cancer spinal metastases: analysis of outcomes and risk of vertebral compression fracture. J Neurosurg Spine. (2014) 21:711-8. doi: 10.3171/2014.7.SPINE13895

19. Garg AK, Shiu AS, Yang J, Wang X-S, Allen P, Brown BW, et al. Phase $1 / 2$ trial of single-session stereotactic body radiotherapy for previously unirradiated spinal metastases. Cancer. (2012) 118:5069-77. doi: 10.1002/cncr.27530

20. Chang U-K, Cho W-I, Kim M-S, Cho CK, Lee DH, Rhee CH. Local tumor control after retreatment of spinal metastasis using stereotactic body radiotherapy; comparison with initial treatment group. Acta Oncol Stockh Swed. (2012) 51:589-95.

21. Gill B, Oermann E, Ju A, Suy S, Yu X, Rabin J, et al. Fiducial-free CyberKnife stereotactic body radiation therapy (SBRT) for single vertebral body metastases: acceptable local control and normal tissue tolerance with 5 fraction approach. Front Oncol. (2012) 2:39. doi: 10.3389/fonc.2012.00039

22. Wang XS, Rhines LD, Shiu AS, Yang JN, Selek U, Gning I, et al. Stereotactic body radiation therapy for management of spinal metastases in patients without spinal cord compression: a phase 1-2 trial. Lancet Oncol. (2012) 13:395-402. doi: 10.1016/S1470-2045(11)70384-9

23. Staehler M, Haseke N, Nuhn P, Tüllmann C, Karl A, Siebels M, et al. Simultaneous anti-angiogenic therapy and single-fraction radiosurgery in clinically relevant metastases from renal cell carcinoma. BJU Int. (2011) 108:673-8. doi: 10.1111/j.1464-410X.2010.09895.x

24. Sahgal A, Ames C, Chou D, Ma L, Huang K, Xu W, et al. Stereotactic body radiotherapy is effective salvage therapy for patients with prior radiation of spinal metastases. Int J Radiat Oncol Biol Phys. (2009) 74:723-31. doi: 10.1016/j.ijrobp.2008.09.020

25. Yamada Y, Bilsky MH, Lovelock DM, Venkatraman ES, Toner S, Johnson $\mathrm{J}$, et al. High-dose, single-fraction image-guided intensity-modulated radiotherapy for metastatic spinal lesions. Int J Radiat Oncol Biol Phys. (2008) 71:484-90. doi: 10.1016/j.ijrobp.2007.11.046

26. Chang EL, Shiu AS, Mendel E, Mathews LA, Mahajan A, Allen PK, et al. Phase I/II study of stereotactic body radiotherapy for spinal metastasis and its pattern of failure. J Neurosurg Spine. (2007) 7:151-60. doi: 10.3171/SPI-07/08/151

27. Gerszten PC, Burton SA, Welch WC, Brufsky AM, Lembersky BC, Ozhasoglu C, et al. Single-fraction radiosurgery for the treatment of spinal breast metastases. Cancer. (2005) 104:2244-54. doi: 10.1002/cncr.21467

28. Ryu S, Rock J, Rosenblum M, Kim JH. Patterns of failure after single-dose radiosurgery for spinal metastasis. J Neurosurg. (2004) 101(Suppl. 3):402-5. doi: 10.1016/j.rpor.2015.03.004

29. Ost P, Jereczek-Fossa BA, As NV, Zilli T, Muacevic A, Olivier $\mathrm{K}$, et al. Progression-free survival following stereotactic body radiotherapy for oligometastatic prostate cancer treatment-naive recurrence: a multi-institutional analysis. Eur Urol. (2016) 69:9-12. doi: 10.1016/j.eururo.2015.07.004

30. Barzilai O, Versteeg AL, Sahgal A, Rhines LD, Bilsky MH, Sciubba DM, et al. Survival, local control, and health-related quality of life in patients with oligometastatic and polymetastatic spinal tumors: a multicenter, international study. Cancer. (2018) 125:770-8. doi: 10.1002/cncr.31870

31. Sahgal A, Roberge D, Schellenberg D, Purdie TG, Swaminath A, Pantarotto J, et al. The Canadian Association of Radiation Oncology scope of practice guidelines for lung, liver and spine stereotactic body radiotherapy. Clin Oncol. (2012) 24:629-39. doi: 10.1016/j.clon.2012.04.006

32. Sahgal A, Larson DA, Chang EL. Stereotactic body radiosurgery for spinal metastases: a critical review. Int J Radiat Oncol Biol Phys. (2008) 71:652-65. doi: 10.1016/j.ijrobp.2008.02.060

33. Expert Panel on Radiation Oncology-Bone Metastases, Lo SS-M, Lutz ST, Chang EL, Galanopoulos N, Howell DD, et al. ACR Appropriateness Criteria ${ }^{\circledR}$ spinal bone metastases. J Palliat Med. (2013) 16:9-19. doi: 10.1089/jpm.2012.0376

34. Spratt DE, Beeler WH, de Moraes FY, Rhines LD, Gemmete JJ, Chaudhary $\mathrm{N}$, et al. An integrated multidisciplinary algorithm for the management of spinal metastases: an International Spine Oncology Consortium report. Lancet Oncol. (2017) 18:e720-30. doi: 10.1016/S1470-2045(17)30612-5

35. Laufer I, Rubin DG, Lis E, Cox BW, Stubblefield MD, Yamada Y, et al. The NOMS framework: approach to the treatment of spinal metastatic tumors. Oncologist. (2013) 18:744-51. doi: 10.1634/theoncologist.2012-0293

36. Nasrallah H, Yamada Y, Laufer I, Bilsky MH. A NOMS framework solution. Int J Radiat Oncol Biol Phys. (2019) 103:17-8. doi: 10.1016/j.ijrobp.2018.09.026

37. Tang C, Hess K, Bishop AJ, Pan HY, Christensen EN, Yang JN, et al. Creation of a prognostic index for spine metastasis to stratify survival in patients treated with spinal stereotactic radiosurgery: secondary analysis of mature prospective trials. Int J Radiat Oncol. (2015) 93:118-25. doi: 10.1016/j.ijrobp.2015.04.050

38. Rich SE, Chow R, Raman S, Liang Zeng K, Lutz S, Lam H, et al. Update of the systematic review of palliative radiation therapy fractionation for bone metastases. Radiother Oncol J Eur Soc Ther Radiol Oncol. (2018) 126:547-57. doi: 10.1016/j.radonc.2018.01.003

39. Jensen G, Tang C, Hess KR, Bishop AJ, Pan HY, Li J, et al. Internal validation of the prognostic index for spine metastasis (PRISM) for stratifying survival in patients treated with spinal stereotactic radiosurgery. J Radiosurg SBRT. (2017) 5:25-34. doi: 10.1016/j.ijrobp.2017.02.085

40. Katagiri H, Takahashi M, Inagaki J, Kobayashi H, Sugiura H, Yamamura S, et al. Clinical results of nonsurgical treatment for spinal metastases. Int J Radiat Oncol Biol Phys. (1998) 42:1127-32.

41. Maranzano E, Latini P. Effectiveness of radiation therapy without surgery in metastatic spinal cord compression: final results from a prospective trial. Int J Radiat Oncol Biol Phys. (1995) 32:959-67.

42. Nguyen Q-N, Shiu AS, Rhines LD, Wang H, Allen PK, Wang XS, et al. Management of spinal metastases from renal cell carcinoma using 
stereotactic body radiotherapy. Int J Radiat Oncol Biol Phys. (2010) 76:118592. doi: 10.1016/j.ijrobp.2009.03.062

43. Fourney DR, Frangou EM, Ryken TC, Dipaola CP, Shaffrey CI, Berven SH, et al. Spinal instability neoplastic score: an analysis of reliability and validity from the spine oncology study group. J Clin Oncol Off J Am Soc Clin Oncol. (2011) 29:3072-7. doi: 10.1200/JCO.2010.34.3897

44. Fisher CG, DiPaola CP, Ryken TC, Bilsky MH, Shaffrey CI, Berven SH, et al. A novel classification system for spinal instability in neoplastic disease: an evidence-based approach and expert consensus from the Spine Oncology Study Group. Spine. (2010) 35:E1221-9. doi: 10.1097/BRS.0b013e3181e16ae2

45. Fisher CG, Schouten R, Versteeg AL, Boriani S, Varga PP, Rhines LD, et al. Reliability of the Spinal Instability Neoplastic Score (SINS) among radiation oncologists: an assessment of instability secondary to spinal metastases. Radiat Oncol Lond Engl. (2014) 9:69. doi: 10.1186/1748-717X-9-69

46. Bilsky MH, Laufer I, Fourney DR, Groff M, Schmidt MH, Varga PP, et al. Reliability analysis of the epidural spinal cord compression scale. J Neurosurg Spine. (2010) 13:324-8. doi: 10.3171/2010.3.SPINE09459

47. Laufer I, Iorgulescu JB, Chapman T, Lis E, Shi W, Zhang Z, et al. Local disease control for spinal metastases following "separation surgery" and adjuvant hypofractionated or high-dose single-fraction stereotactic radiosurgery: outcome analysis in 186 patients. J Neurosurg Spine. (2013) 18:207-14. doi: 10.3171/2012.11.SPINE12111

48. Klekamp J, Samii H. Surgical results for spinal metastases. Acta Neurochir (Wien). (1998) 140:957-67. doi: 10.3171/2016.6.FOCUS16166

49. Itshayek E, Yamada J, Bilsky M, Schmidt M, Shaffrey C, Gerszten $\mathrm{P}$, et al. Timing of surgery and radiotherapy in the management of metastatic spine disease: a systematic review. Int J Oncol. (2010) 36:533-44. doi: $10.21037 /$ jss.2018.05.05

50. Tseng C-L, Eppinga W, Charest-Morin R, Soliman H, Myrehaug S, Maralani PJ, et al. Spine stereotactic body radiotherapy: indications, outcomes, and points of caution. Glob Spine J. (2017) 7:179-97. doi: 10.1177/2192568217694016

51. Al-Omair A, Masucci L, Masson-Cote L, Campbell M, Atenafu EG, Parent A, et al. Surgical resection of epidural disease improves local control following postoperative spine stereotactic body radiotherapy. Neuro-Oncol. (2013) 15:1413-9. doi: 10.1093/neuonc/not101

52. Hyde D, Lochray F, Korol R, Davidson M, Wong CS, Ma L, et al. Spine stereotactic body radiotherapy utilizing cone-beam CT image-guidance with a robotic couch: intrafraction motion analysis accounting for all six degrees of freedom. Int J Radiat Oncol Biol Phys. (2012) 82:e555-62. doi: 10.1016/j.ijrobp.2011.06.1980

53. Tseng C-L, Sussman MS, Atenafu EG, Letourneau D, Ma L, Soliman H, et al. Magnetic resonance imaging assessment of spinal cord and cauda equina motion in supine patients with spinal metastases planned for spine stereotactic body radiation therapy. Int J Radiat Oncol Biol Phys. (2015) 91:995-1002. doi: 10.1016/j.ijrobp.2014.12.037

54. Yenice KM, Lovelock DM, Hunt MA, Lutz WR, Fournier-Bidoz N, Hua $\mathrm{C}-\mathrm{H}$, et al. CT image-guided intensity-modulated therapy for paraspinal tumors using stereotactic immobilization. Int J Radiat Oncol Biol Phys. (2003) 55:583-93. doi: 10.1227/01.NEU.0000279970.10309.B5

55. Li W, Sahgal A, Foote M, Millar B-A, Jaffray DA, Letourneau D. Impact of immobilization on intrafraction motion for spine stereotactic body radiotherapy using cone beam computed tomography. Int J Radiat Oncol Biol Phys. (2012) 84:520-6. doi: 10.1016/j.ijrobp.2011.12.039

56. Finnigan R, Lamprecht B, Barry T, Jones K, Boyd J, Pullar A, et al. Inter- and intra-fraction motion in stereotactic body radiotherapy for spinal and paraspinal tumours using cone-beam $\mathrm{CT}$ and positional correction in six degrees of freedom. J Med Imaging Radiat Oncol. (2016) 60:112-8. doi: 10.1111/1754-9485.12353

57. Cox BW, Spratt DE, Lovelock M, Bilsky MH, Lis E, Ryu S, et al. International Spine Radiosurgery Consortium consensus guidelines for target volume definition in spinal stereotactic radiosurgery. Int J Radiat Oncol Biol Phys. (2012) 83:e597-605. doi: 10.1016/j.jirobp.2012.03.009

58. Chan MW, Thibault I, Atenafu EG, Yu E, John Cho BC, Letourneau D, et al. Patterns of epidural progression following postoperative spine stereotactic body radiotherapy: implications for clinical target volume delineation. $J$ Neurosurg Spine. (2016) 24:652-9. doi: 10.3171/2015.6.SPINE15294
59. Redmond KJ, Robertson S, Lo SS, Soltys SG, Ryu S, McNutt T, et al. Consensus contouring guidelines for postoperative stereotactic body radiation therapy for metastatic solid tumor malignancies to the spine. Int J Radiat Oncol Biol Phys. (2017) 97:64-74. doi: 10.1016/j.ijrobp.2016.09.014

60. Faruqi S, Tseng C-L, Whyne C, Alghamdi M, Wilson J, Myrehaug S, et al. Vertebral compression fracture after spine stereotactic body radiation therapy: a review of the pathophysiology and risk factors. Neurosurgery. (2018) 83:314-22. doi: 10.1093/neuros/nyx493

61. Redmond KJ, Sahgal A, Foote M, Knisely J, Gerszten PC, Chao ST, et al. Single versus multiple session stereotactic body radiotherapy for spinal metastasis: the risk-benefit ratio. Future Oncol Lond Engl. (2015) 11:2405-15. doi: $10.2217 /$ fon. 15.160

62. Benedict SH, Yenice KM, Followill D, Galvin JM, Hinson W, Kavanagh B, et al. Stereotactic body radiation therapy: the report of AAPM Task Group 101. Med Phys. (2010) 37:4078-101. doi: 10.1118/1.3438081

63. Sahgal A, Ma L, Weinberg V, Gibbs IC, Chao S, Chang U-K, et al. Reirradiation human spinal cord tolerance for stereotactic body radiotherapy. Int J Radiat Oncol Biol Phys. (2012) 82:107-16. doi: 10.1016/j.ijrobp.2010.08.021

64. Sahgal A, Ma L, Gibbs I, Gerszten PC, Ryu S, Soltys S, et al. Spinal cord tolerance for stereotactic body radiotherapy. Int J Radiat Oncol Biol Phys. (2010) 77:548-53. doi: 10.1016/j.ijrobp.2009.05.023

65. Chang EL, Shiu AS, Lii M-F, Rhines LD, Mendel E, Mahajan A, et al. Phase I clinical evaluation of near-simultaneous computed tomographic imageguided stereotactic body radiotherapy for spinal metastases. Int J Radiat Oncol Biol Phys. (2004) 59:1288-94. doi: 10.1016/j.ijrobp.2004.04.025

66. Degen JW, Gagnon GJ, Voyadzis J-M, McRae DA, Lunsden M, Dieterich $\mathrm{S}$, et al. CyberKnife stereotactic radiosurgical treatment of spinal tumors for pain control and quality of life. J Neurosurg Spine. (2005) 2:540-9. doi: 10.3171/spi.2005.2.5.0540

67. Amini B, Beaman CB, Madewell JE, Allen PK, Rhines LD, Tatsui CE, et al. Osseous pseudoprogression in vertebral bodies treated with stereotactic radiosurgery: a secondary analysis of prospective phase I/II clinical trials. AJNR Am J Neuroradiol. (2016) 37:387-92. doi: 10.3174/ajnr.A4528

68. Bahig H, Simard D, Létourneau L, Wong P, Roberge D, Filion E, et al. A study of pseudoprogression after spine stereotactic body radiation therapy. Int $J$ Radiat Oncol Biol Phys. (2016) 96:848-56. doi: 10.1016/j.ijrobp.2016.07.034

69. Jabehdar Maralani P, Winger K, Symons S, Machnowska M, Heyn C, Helmi $\mathrm{A}$, et al. Incidence and time of onset of osseous pseudoprogression in patients with metastatic spine disease from renal cell or prostate carcinoma after treatment with stereotactic body radiation therapy. Neurosurgery. (2018) 84:647-54. doi: 10.1093/neuros/nyy075

70. Thibault I, Chang EL, Sheehan J, Ahluwalia MS, Guckenberger M, Sohn $\mathrm{M}-\mathrm{J}$, et al. Response assessment after stereotactic body radiotherapy for spinal metastasis: a report from the SPIne response assessment in Neuro-Oncology (SPINO) group. Lancet Oncol. (2015) 16:e595-603. doi: 10.1016/S1470-2045(15)00166-7

71. Chow E, Hoskin P, Mitera G, Zeng L, Lutz S, Roos D, et al. Update of the international consensus on palliative radiotherapy endpoints for future clinical trials in bone metastases. Int J Radiat Oncol Biol Phys. (2012) 82:1730-7. doi: 10.1016/j.ijrobp.2011.02.008

72. Amdur RJ, Bennett J, Olivier K, Wallace A, Morris CG, Liu C, et al. A prospective, phase II study demonstrating the potential value and limitation of radiosurgery for spine metastases. Am J Clin Oncol. (2009) 32:515-20. doi: 10.1097/COC.0b013e318194f70f

73. Hall WA, Stapleford LJ, Hadjipanayis CG, Curran WJ, Crocker I, Shu H-KG. Stereotactic body radiosurgery for spinal metastatic disease: an evidence-based review. Int J Surg Oncol. (2011) 2011:979214. doi: 10.1155/2011/979214

74. Ghia AJ, Chang EL, Bishop AJ, Pan HY, Boehling NS, Amini B, et al. Singlefraction versus multifraction spinal stereotactic radiosurgery for spinal metastases from renal cell carcinoma: secondary analysis of Phase I/II trials. J Neurosurg Spine. (2016) 24:829-36. doi: 10.3171/2015.8.SPINE15844

75. Folkert MR, Bilsky MH, Tom AK, Oh JH, Alektiar KM, Laufer I, et al. Outcomes and toxicity for hypofractionated and single-fraction imageguided stereotactic radiosurgery for sarcomas metastasizing to the spine. Int $J$ Radiat Oncol Biol Phys. (2014) 88:1085-91. doi: 10.1016/j.ijrobp.2013.12.042 
76. Gerszten PC, Burton SA, Quinn AE, Agarwala SS, Kirkwood JM. Radiosurgery for the treatment of spinal melanoma metastases. Stereotact Funct Neurosurg. (2005) 83:213-21. doi: 10.1159/000091952

77. Tao R, Bishop AJ, Brownlee Z, Allen PK, Settle SH, Chang EL, et al. Stereotactic body radiation therapy for spinal metastases in the postoperative setting: a secondary analysis of mature phase 1-2 trials. Int J Radiat Oncol Biol Phys. (2016) 95:1405-13.

78. Redmond KJ, Lo SS, Fisher C, Sahgal A. Postoperative Stereotactic Body Radiation Therapy (SBRT) for spine metastases: a critical review to guide practice. Int J Radiat Oncol Biol Phys. (2016) 95:1414-28. doi: 10.1016/j.ijrobp.2016.03.022

79. Huisman M, van den Bosch MAAJ, Wijlemans JW, van Vulpen M, van der Linden YM, Verkooijen HM. Effectiveness of reirradiation for painful bone metastases: a systematic review and meta-analysis. Int J Radiat Oncol Biol Phys. (2012) 84:8-14. doi: 10.1016/j.ijrobp.2011.10.080

80. Myrehaug S, Sahgal A, Hayashi M, Levivier M, Ma L, Martinez R, et al. Reirradiation spine stereotactic body radiation therapy for spinal metastases: systematic review. J Neurosurg Spine. (2017) 27:428-35. doi: 10.3171/2017.2.SPINE16976

81. Hashmi A, Guckenberger M, Kersh R, Gerszten PC, Mantel F, Grills IS, et al. Re-irradiation stereotactic body radiotherapy for spinal metastases: a multi-institutional outcome analysis. J Neurosurg Spine. (2016) 25:646-53. doi: 10.1016/j.ijrobp.2016.06.301

82. Chow E, Linden YM van der, Roos D, Hartsell WF, Hoskin P, Wu JSY, et al. Single versus multiple fractions of repeat radiation for painful bone metastases: a randomised, controlled, non-inferiority trial. Lancet Oncol. (2014) 15:164-71. doi: 10.1016/S1470-2045(13)70556-4

83. Gerszten PC, Burton SA, Ozhasoglu C, Welch WC. Radiosurgery for spinal metastases: clinical experience in 500 cases from a single institution. Spine. (2007) 32:193-9. doi: 10.1097/01.brs.0000251863.76595.a2

84. Sprave T, Verma V, Förster R, Schlampp I, Bruckner T, Bostel T, et al. Randomized phase II trial evaluating pain response in patients with spinal metastases following stereotactic body radiotherapy versus threedimensional conformal radiotherapy. Radiother Oncol J Eur Soc Ther Radiol Oncol. (2018) 128:274-82. doi: 10.1016/j.radonc.2018.04.030

85. Ryu S, Pugh SL, Gerszten PC, Yin F-F, Timmerman RD, Hitchcock YJ, et al. RTOG 0631 phase 2/3 study of image guided stereotactic radiosurgery for localized (1-3) spine metastases: phase 2 results. Pract Radiat Oncol. (2014) 4:76-81. doi: 10.1016/j.prro.2013.05.001

86. Study Comparing Stereotactic Body Radiotherapy vs Conventional Palliative Radiotherapy (CRT) for Spinal Metastases - Full Text View ClinicalTrials.gov [Internet]. Available online at: https://clinicaltrials.gov/ ct2/show/NCT02512965 (cited January 20, 2019).

87. Guckenberger M, Wulf J, Mueller G, Krieger T, Baier K, Gabor M, et al. Dose-response relationship for image-guided stereotactic body radiotherapy of pulmonary tumors: relevance of $4 \mathrm{D}$ dose calculation. Int J Radiat Oncol Biol Phys. (2009) 74:47-54. doi: 10.1016/j.ijrobp.2008. 06.1939

88. Sprave T, Verma V, Förster R, Schlampp I, Bruckner T, Bostel T, et al. Quality of life following stereotactic body radiotherapy versus three-dimensional conformal radiotherapy for vertebral metastases: secondary analysis of an exploratory phase II randomized trial. Anticancer Res. (2018) 38:4961-8. doi: 10.21873/anticanres

89. Zeng KL, Myrehaug S, Soliman H, Tseng C-L, Atenafu EG, Campbell M, et al. Stereotactic body radiotherapy for spinal metastases at the extreme ends of the spine: imaging-based outcomes for cervical and sacral metastases. Neurosurgery. (2018). doi: 10.1093/neuros/nyy393. [Epub ahead of print].

90. Chow E, Meyer RM, Ding K, Nabid A, Chabot P, Wong P, et al. Dexamethasone in the prophylaxis of radiation-induced pain flare after palliative radiotherapy for bone metastases: a double-blind, randomised placebo-controlled, phase 3 trial. Lancet Oncol. (2015) 16:1463-72. doi: 10.1016/S1470-2045(15)00199-0
91. Balagamwala EH, Naik M, Reddy CA, Angelov L, Suh JH, Djemil T, et al. Pain flare after stereotactic radiosurgery for spine metastases. J Radiosurgery SBRT. (2018) 5:99-105.

92. Ryu S, Fang Yin F, Rock J, Zhu J, Chu A, Kagan E, et al. Image-guided and intensity-modulated radiosurgery for patients with spinal metastasis. Cancer. (2003) 97:2013-8. doi: 10.1002/cncr.11296

93. Chiang A, Zeng L, Zhang L, Lochray F, Korol R, Loblaw A, et al. Pain flare is a common adverse event in steroid-naïve patients after spine stereotactic body radiation therapy: a prospective clinical trial. Int J Radiat Oncol Biol Phys. (2013) 86:638-42. doi: 10.1016/j.ijrobp.2013.03.022

94. Khan L, Chiang A, Zhang L, Thibault I, Bedard G, Wong E, et al. Prophylactic dexamethasone effectively reduces the incidence of pain flare following spine stereotactic body radiotherapy (SBRT): a prospective observational study. Support Care Cancer Off J Multinatl Assoc Support Care Cancer. (2015) 23:2937-43. doi: 10.1007/s00520-015-2659-Z

95. Cunha MVR, Al-Omair A, Atenafu EG, Masucci GL, Letourneau D, Korol $\mathrm{R}$, et al. Vertebral compression fracture (VCF) after spine stereotactic body radiation therapy (SBRT): analysis of predictive factors. Int J Radiat Oncol Biol Phys. (2012) 84:e343-9. doi: 10.1016/j.ijrobp.2012.04.034

96. Rose PS, Laufer I, Boland PJ, Hanover A, Bilsky MH, Yamada J, et al. Risk of fracture after single fraction image-guided intensity-modulated radiation therapy to spinal metastases. J Clin Oncol Off J Am Soc Clin Oncol. (2009) 27:5075-9. doi: 10.1200/JCO.2008.19.3508

97. Chow E, Harris K, Fan G, Tsao M, Sze WM. Palliative radiotherapy trials for bone metastases: a systematic review. J Clin Oncol Off J Am Soc Clin Oncol. (2007) 25:1423-36. doi: 10.1016/j.clon.2011.11.004

98. Sahgal A, Atenafu EG, Chao S, Al-Omair A, Boehling N, Balagamwala $\mathrm{EH}$, et al. Vertebral compression fracture after spine stereotactic body radiotherapy: a multi-institutional analysis with a focus on radiation dose and the spinal instability neoplastic score. J Clin Oncol. (2013) 31:3426-31. doi: 10.1200/JCO.2013.50.1411

99. Lee S-H, Tatsui CE, Ghia AJ, Amini B, Li J, Zavarella SM, et al. Can the spinal instability neoplastic score prior to spinal radiosurgery predict compression fractures following stereotactic spinal radiosurgery for metastatic spinal tumor?: a post hoc analysis of prospective phase II single-institution trials. J Neurooncol. (2016) 126:509-17. doi: 10.1007/s11060-015-1990-Z

100. Thibault I, Whyne CM, Zhou S, Campbell M, Atenafu EG, Myrehaug S, et al. Volume of lytic vertebral body metastatic disease quantified using computed tomography-based image segmentation predicts fracture risk after spine stereotactic body radiation therapy. Int J Radiat Oncol Biol Phys. (2017) 97:75-81. doi: 10.1016/j.ijrobp.2016.09.029

101. Sprave T, Verma V, Förster R, Schlampp I, Hees K, Bruckner T, et al. Local response and pathologic fractures following stereotactic body radiotherapy versus three-dimensional conformal radiotherapy for spinal metastases - a randomized controlled trial. BMC Cancer 18:859. doi: 10.1186/s12885-018-4777-8

102. Sahgal A, Weinberg V, Ma L, Chang E, Chao S, Muacevic A, et al. Probabilities of radiation myelopathy specific to stereotactic body radiation therapy to guide safe practice. Int J Radiat Oncol Biol Phys. (2013) 85:341-7. doi: $10.1016 /$ j.ijrobp.2012.05.00

Conflict of Interest Statement: The authors declare that the research was conducted in the absence of any commercial or financial relationships that could be construed as a potential conflict of interest.

Copyright (c) 2019 Zeng, Tseng, Soliman, Weiss, Sahgal and Myrehaug. This is an open-access article distributed under the terms of the Creative Commons Attribution License (CC BY). The use, distribution or reproduction in other forums is permitted, provided the original author(s) and the copyright owner(s) are credited and that the original publication in this journal is cited, in accordance with accepted academic practice. No use, distribution or reproduction is permitted which does not comply with these terms. 